\title{
Coexistência de pênfigo vulgar e infecção pelo vírus herpes simples na mucosa oral
}

\author{
Coexistence of pemphigus vulgaris and herpes simplex virus infection in oral mucosa \\ Adrianna Milagres'; Ana Flávia Schueler de Assumpção Leite²; Elisa Estrella³; Flávia Dantas Soares4; \\ Eliane Pedra Dias ${ }^{5}$; Simone de Queiroz Chaves Lourenço ${ }^{6}$
}

\begin{tabular}{l|l}
\multicolumn{1}{c|}{ Unitermos } & resumo \\
\hline $\begin{array}{l}\text { Pênfigo } \\
\text { Herpes simples }\end{array}$ & $\begin{array}{l}\text { O pênfigo vulgar é uma doença mucocutânea, imunomediada, caracterizada por lesões vesiculobolhosas, } \\
\text { enquanto a infecção pelo vírus herpes simples (HSV) é comum na cavidade oral. A coexistência das duas } \\
\text { doenças tem sido relatada por alguns autores. Este artigo relata o caso de um paciente com múltiplas } \\
\text { lesões em várias áreas da mucosa oral, cujo procedimento foi raspagem e biópsia incisional, que resultou } \\
\text { no diagnatologia } \\
\text { Mucosa bucal } \\
\text { das doenças e a identificação citopatológica de duas populações celulares com aspectos morfológicos } \\
\text { distintos e característicos, capazes de determinar o correto diagnóstico, sendo fundamental para a } \\
\text { conduta e terapêutica adequada. }\end{array}$
\end{tabular}

abstract

Pemphigus vulgaris is an autoimmune mucocutaneous disease, characterized by vesiculobullous lesions. Herpes simplex virus (HSV) infection is common in the oral cavity and the coexistence of pemphigus vulgaris and HSV infection has been reported by some authors. In this work, we report a case of a patient with multiple lesions involving several areas of the oral mucous membrane. Based on scraping cytology and incisional biopsy findings, the diagnosis was pemphigus vulgaris associated with HSV infection. We call attention to the uncommon association of both diseases and the cytological identification of two cell populations with different and characteristic morphological aspects, able enough to establish the correct diagnosis and define an appropriate therapeutic approach. key words

Pemphigus

Herpes simplex

Cytopathology

Bucal mucosa

\section{Introdução}

O pênfigo vulgar é uma doença mucocutânea caracterizada por lesões vesiculobolhosas decorrentes da produção anormal de auto-anticorpos contra glicoproteínas da superfície das células epiteliais (desmogleína 1 e 3$)^{(8,13)}$. Como conseqüência, observa-se agressão imunológica sobre os desmossomos, ocasionando perda de adesão celular e formação de bolha intraepitelia|(10).

Clinicamente, apresentam-se como bolhas e vesículas que se rompem facilmente, formando várias úlceras de contorno e margens irregulares ${ }^{(11)}$. 
Ao exame histopatológico verifica-se fenda suprabasal, acantólise e intenso infiltrado inflamatório(11, 13). As células acantolíticas também são identificadas na citopatologia, na qual são observadas solitárias e/ou em pequenos grupamentos, apresentando núcleo vesicular com nucléolo proeminente, fina membrana nuclear e margens citoplasmáticas bem definidas, com formato arredondado ${ }^{(6,17)}$.

O tratamento do pênfigo vulgar consiste no uso de corticosteróides, que pode ser de forma tópica ou sistêmica, dependendo da gravidade das lesões e da necessidade do paciente ${ }^{(13)}$.

A infecção pelo vírus herpes simples (HSV) tem sido relatada associada a lesões de pacientes acometidos por pênfigo vulgar ${ }^{(5,14,15)}$. Após a infecção inicial pelo HSV ocorrem períodos da latência e de reativação. Geralmente, a reativação decorre de fatores que debilitam o sistema imunológico, como exposição solar, frio, estresse emocional, trauma, fadiga, febre e outras condições sistêmicas, caracterizando-se por pequenas vesículas que podem acometer regiões intra e perioral| ${ }^{10,16)}$.

Microscopicamente, os ceratinócitos infectados pelo HSV exibem alterações representativas do efeito citopático do vírus, evidenciadas tanto na histopatologia como na citopatologia. São observados aumento de volumes celular e nuclear, multinucleação com amoldamento, inclusões intranucleares descritas como núcleo em "vidro fosco" (desarranjo na cromatina com localização marginal e o centro homogêneo com aspecto de vidro despolido), bem como inclusão do tipo A de Cowdry (inclusão eosinofílica e presença de espaço entre a inclusão e a membrana nuclear, formando um halo) $)^{(2-4,12)}$.

A medicação instituída para o tratamento da infecção pelo HSV é o aciclovir, que pode ser administrado de forma tópica ou sistêmica, conforme a gravidade do caso ${ }^{(16)}$.

Este trabalho relata o caso clínico de coexistência de pênfigo vulgar e herpes simples oral, cujo diagnóstico foi definido por exames citopatológico e histopatológico. Será discutida a importância de se ter o diagnóstico de herpes simples em mente nos pacientes com hipótese clínica e/ou com diagnóstico de pênfigo vulgar, e ainda a importância do exame citopatológico no diagnóstico e na identificação das duas condições patológicas.

\section{Relato do caso}

Paciente, sexo masculino, branco, 75 anos, apresentou-se no ambulatório de Diagnóstico Oral do Hospital
Universitário Antônio Pedro (HUAP) com queixa de disfagia e lesões dolorosas na cavidade bucal, que sangravam com facilidade há 12 meses. Negava qualquer doença associada ou uso de medicações no período, além de história de herpes simples labial.

Ao exame clínico, foram observadas múltiplas lesões ulceradas de tamanhos variados, recobertas por membrana esbranquiçada, localizadas no soalho bucal, ventre e dorso da língua, mucosas jugal e labial, rebordo alveolar e palato mole (Figura 1). As hipóteses diagnósticas clínicas foram pênfigo vulgar e penfigóide bolhoso.

O procedimento adotado no caso em questão foi raspado das lesões para confecção de esfregaços e biópsia incisional da lesão do lábio inferior.

$\mathrm{Na}$ citopatologia, verificou-se presença de abundantes leucócitos (com predomínio de polimorfonucleares), células acantolíticas solitárias e em pequenos grupos e ceratinócitos com efeito citopático correspondente ao HSV (Figuras 2 e 3). Já o exame histopatológico revelou acantólise, com formação de fendas suprabasais acantolíticas, infiltrado inflamatório crônico e extensa área de ulceração, além de ceratinócitos exibindo alterações compatíveis com o efeito citopático do HSV, sendo o diagnóstico definitivo de pênfigo vulgar associado à infecção pelo vírus Herpes simplex (Figuras 4 e $\mathbf{5}$ ).

O paciente foi encaminhado para o Serviço de Dermatologia, porém não foram evidenciadas lesões cutâneas. Também foi realizada endoscopia digestiva, que constatou apenas gastrite leve, mas sem nenhuma alteração esofágica.

Para o tratamento utilizou-se propionato de clobetasol (creme), 3 vezes ao dia, e aciclovir $200 \mathrm{mg}$ por via oral, cinco vezes ao dia, durante duas semanas, que resultou em melhora das lesões. O aciclovir foi suspenso, mas o

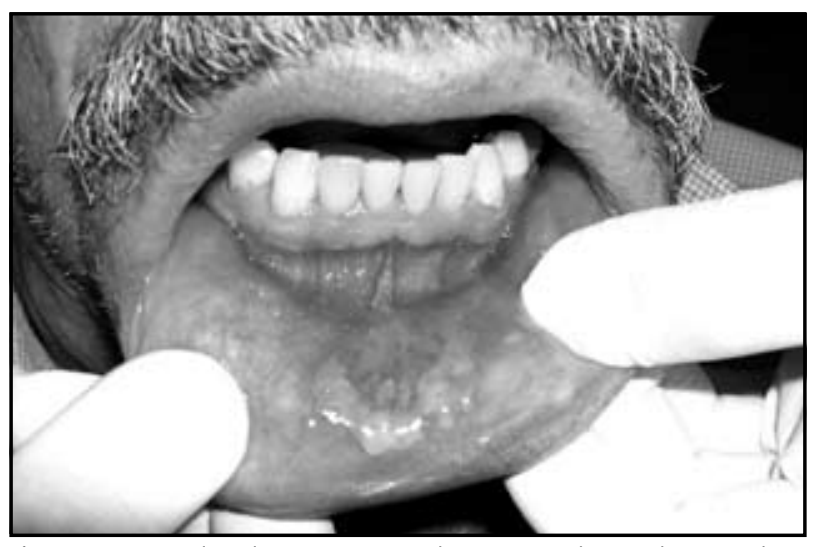

Figura 1 - Lesão ulcerada, eritematosa recoberta por membrana esbranquiçada na mucosa interna do lábio inferior 


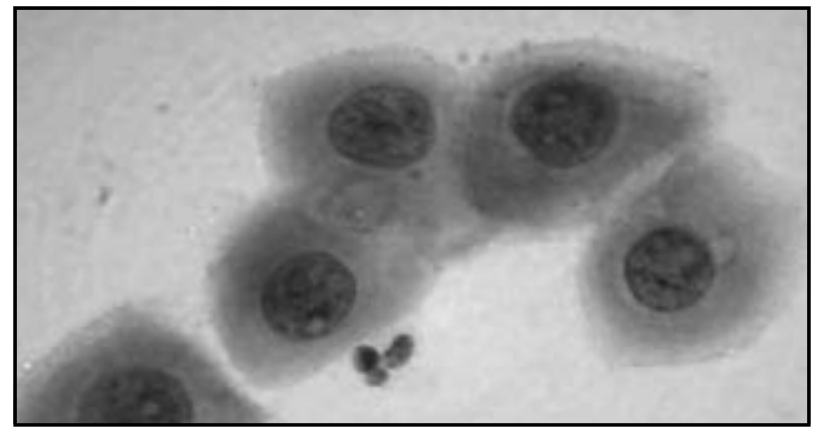

Figura 2 - Grupo de células acantolíticas (Papanicolaou, 100x)

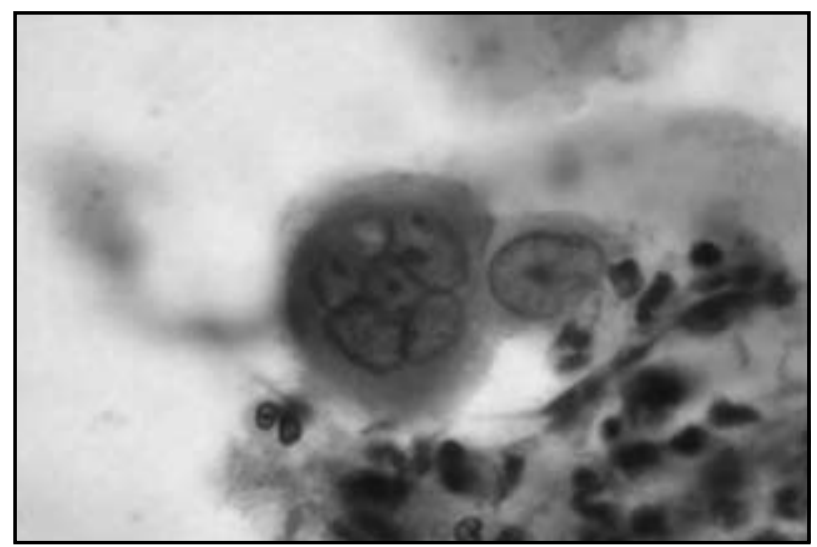

Figura 3 - Célula multinucleada com amoldamento nuclear e leucócitos mononucleares e polimorfonucleares (Papanicolaou, 100x)

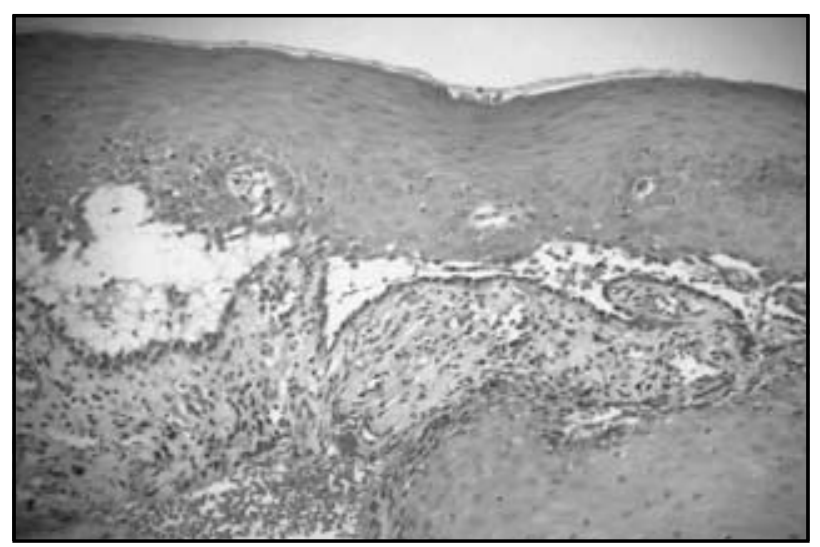

Figura 4 - Fenda suprabasal com preservação da camada basal (HE, 10x)

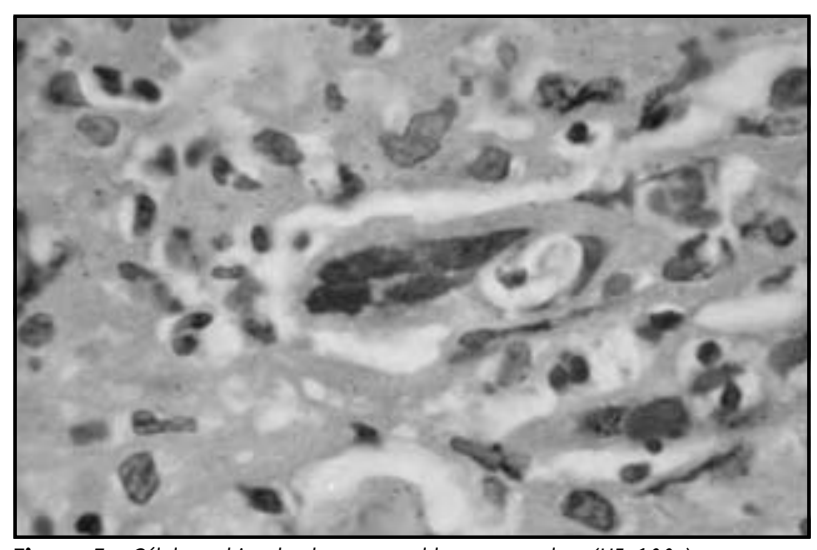

Figura 5 - Célula multinucleada com amoldamento nuclear (HE, 100x) propionato de clobetasol foi mantido por mais uma semana, com diminuição gradativa da dose até a regressão total das lesões (Figura 6).

Após quatro meses de acompanhamento houve recidiva das lesões, sendo então realizado exame citopatológico, o qual mostrou apenas células acantolíticas e leucócitos. Prescreveu-se prednisona na dose de $60 \mathrm{mg} /$ dia, com regressão completa das lesões em uma semana, e a medicação foi gradualmente descontinuada.

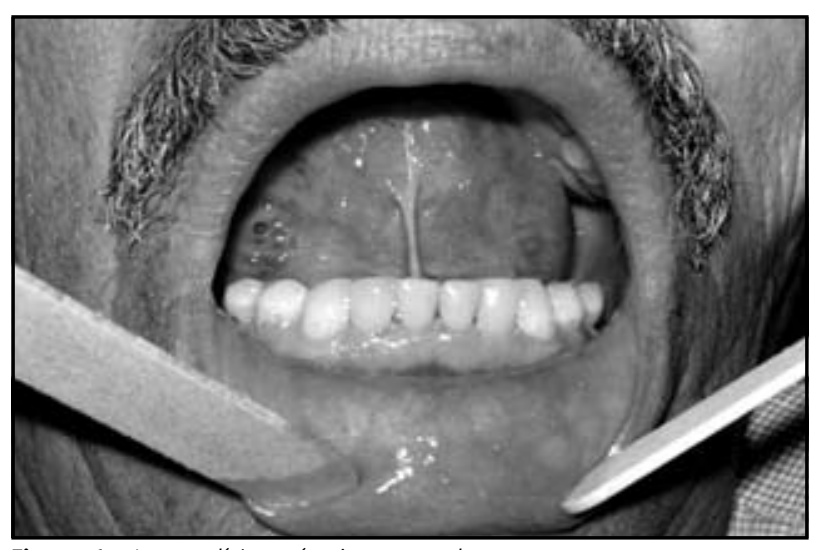

Figura 6 - Aspecto clínico após três semanas de tratamento

\section{Discussão}

Na maioria das vezes, as lesões orais típicas de pênfigo vulgar não costumam simular lesões de herpes simples. As lesões de pênfigo vulgar são úlceras grandes (> $20 \mathrm{~mm}$ ), apresentam formato irregular, não-agrupadas, e são circundadas por mucosa normal. As lesões de herpes simples são ulcerações pequenas (1 a $3 \mathrm{~mm}$ ), arredondadas, agrupadas (na infecção recorrente) ou não-agrupadas (na primoinfecção) e circundadas por mucosa inflamada ${ }^{(7)}$.

Algumas vezes, as lesões ulceradas não apresentam características tão definidas, e a ausência dos aspectos clássicos que determinariam cada uma das doenças passa a dificultar o diagnóstico clínico, como no caso relatado, em que o paciente não apresentava lesões características de herpes simples. Assim, a presença de herpes simples oral num paciente com pênfigo vulgar pode não ser diagnosticada.

A coexistência do pênfigo vulgar e da infecção pelo HSV deve ser considerada, principalmente em pacientes controlados com terapia imunossupressora, em geral corticóides orais, que passam a apresentar abruptamente lesões orais ulceradas e dolorosas. Nesse caso, se houver infecção pelo HSV e não for detectada, pode-se pensar em recidiva das lesões de pênfigo e, dessa forma, até aumentar a dose da medicação imunossupressora. Numa segunda situação, quando o paciente com lesões ativas de pênfigo vulgar apresentar alguma piora do quadro ou dificuldade de tratamento ${ }^{(7,9)}$. 
A coexistência de pênfigo vulgar e herpes simples oral foi descrita pela primeira vez por Marton (apud Schulpen et al. $\left.{ }^{(14)}\right)$, em 1963, e desde então poucos casos foram relatados. O mecanismo pelo qual o processo ocorre é controverso. A maioria dos autores acredita que a terapia imunossupressora usada para o tratamento do pênfigo vulgar propiciaria a manifestação de lesões pelo $\operatorname{HSV}(5,9,15)$.

Isso não se confirma no caso relatado, pois o paciente não estava fazendo uso de nenhum tipo de medicação, sugerindo que a manifestação do HSV possa ter sido provocada por outro fator imunossupressor não percebido ou reportado pelo paciente, ou, talvez, tenha sido ocasionada pelo próprio pênfigo vulgar. Além disso, quando houve recidiva das lesões, quatro meses após a corticoterapia, a infecção pelo HSV não foi detectada na citopatologia.

Vários métodos são utilizados para o diagnóstico das duas condições, como exame histopatológico, meios de cultura, reação em cadeia da polimerase (PCR) para iden- tificação da infecção pelo HSV e imunofluorescência, que detecta os auto-anticorpos no pênfigo vulgar ${ }^{(1,9)}$.

Contudo, por meio da análise citopatológica podem ser evidenciadas duas populações celulares representativas de pênfigo e de infecção pelo herpes simples, ou seja, as células acantolíticas e as células multinucleadas com amoldamento e com inclusão viral, possibilitando assim o diagnóstico compatível com a coexistência das doenças. A citopatologia também foi de grande valia durante a recidiva das lesões, verificando os aspectos do pênfigo vulgar e a ausência da infecção pelo HSV, evitando a realização de nova biópsia.

Também se deve destacar a importância da citopatologia por ser capaz de proporcionar uma orientação segura do diagnóstico e do acompanhamento nos casos de recidiva. Por ser um método rápido, de fácil execução e de baixo custo, possibilita a agilidade na conduta e terapêutica adequadas para o paciente, estando acessível para a maioria dos serviços.

\section{Referências}

1. BROWN, P.; TAYLOR, B. Herpes simplex infection associated with pemphigus vulgaris. J Am Acad Dermatol, v. 21, p. 1126-8, 1989.

2. DIAS, E.P. et al. Diagnóstico clínico e cito-histopatológico das manifestações bucais na AIDS. JBDST, v. 10, n. 1, p. 10-6, 1998.

3. DIAS, E.P.; TORRES, S. Aspectos clínicos, anatomopatológicos e citopatológicos das lesões bucais na infecção pelo HIV. In: OLIVEIRA, C.A.B. ATLAIDS - Atlas de patologia da síndrome da imunodeficiência adquirida. São Paulo: Atheneu, 2005. p. 134-56.

4. DIAS E.P. et al. Detecção dos efeitos citopáticos dos vírus HSV, EBV e CMV em lesões orais através de exames histo e citopatológicos. JBM, v. 89, n 3, 2005.

5. GRUNWALD, M.H. et al. Association of pemphigus vulgaris and herpes simplex virus infection. Int J Dermatol, v. 25, n. 6, p. 392-3, 1986.

6. GUPTA, S. et al. Acantholytic cells exfoliated from pemphigus vulgaris of the uterine cervix: a case report. Acta Cytol, v. 47, n. 5, p. 795-8, 2003.

7. HALE, E.K.; BYSTRYN, J.C. Atypical herpes simplex can mimic a flare of disease activity in patients with pemphigus vulgaris. J Eur Acad Dermatol Venereol, v. 13, n. 3, p. 221-3, 1999.

8. MIMOUNI, D. et al. Pemphigus. Dermat Therapy, v. 15, p. 362-8, 2002.

9. NEGOSANTI, M. et al. Severe herpetic gingivostomatitis associated with pemphigus vulgaris. Arch Dermatol, v. 120, n. 4, p. 540-2, 1984.

10. NEVILLE, B.W. et al. Patologia oral e maxilofacial. 2 ed. Rio de Janeiro: Guanabara Koogan, 2004.

11. ODELL, E.W.; MORGAN, P.R. Biopsy pathology of the oral tissues. London: Chapman \& Hall, 1998.

12. POWERS, C.N. Diagnosis of infectious diseases: a cytopathologist's perspective. Clin Microbiol Reviews, v. 11, n. 2, p. 341-65, 1998

13. ROBINSON, N.A. et al. Oral pemphigus vulgaris: a case report and literature update. Ann Acad Med Singapore, v. 33, suppll. S, p. 63-8, 2004.

14. SCHULPEN, E.M. et al. Detection of herpes simples virus in exacerbated pemphigus vulgaris by polymerase chain reaction. Dermatology, v. 192, p. 312-6, 1996.

15. TAKAHASHI, I. et al. Coexistence of Pemphigus vulgaris and Herpes simplex virus infection in oral mucosa diagnosed by cytology, immunohistochemistry and polymerase chain reaction. Diag Cytopathol, v. 19, n. 6, p. 446-50, 1998.

16. TILLISS, T.S.I. et al. Differential diagnoses: is it herpes or aphthous? J Contemporary Dent Pract, v. 3, n. 1, p. 1-10, 2002

17. WRIGTH, C. et al. Pemphigus vulgaris of the uterine cervix revisited: case report and review of the literature. Diag Cytopathol, v. 22, n. 5, p. 304-7, 2000.
Endereço para correspondência

Simone de Queiroz Chaves Lourenço

Departamento de Patologia - Hospital Universitário Antônio Pedro (HUAP)

Rua Marquês de Paraná, $303-4^{\circ}$ andar

CEP: 24033-900 - Niterói-R

E-mail: mpts@@vm.uff.br 